\title{
LA FORMA HUMANA
}

\section{Germán Enrique Beltrán}

Es probablemente muy cierto que la historia del pensamiento humano, los desarrollos más fructíferos frecuentemente tienen lugar en los puntos donde se encuentran dos líneas de pensamiento diferente. Estas líneas pueden tener sus raíces en partes muy diferentes de la cultura humana, en diferentes épocas o en diferentes ambientes culturales o tradiciones religiosas. Por tanto si realmente pueden encontrarse, o sea, si al menos se relacionan unas con otras para que puedan tener lugar en verdadera interacción, entonces se puede esperar que a estos sucedan nuevos e interesantes progresos.

Werner Heisenberg.

Como pedagogos constituimos una gran organización de sinceros aspirantes al poder que proviene del conocimiento, y el conocimiento es el único poder que necesitamos.

Nos circundan por todos lados las más poderosas fuerzas, podemos pensar que la dinámica es un poder maravilloso, una fuerza de gran potencia, cuando se le deja libre, pero este poder no es nada en comparación con la potencia del poder y fuerza contenidos en el electrón invisible o átomo de materia, si pudiéramos liberarlo con tal facilidad como lo hacemos con la fuerza de la dinámica. La fuerza llamada de gravitación no es más potente que la fuerza que cualquier motor eléctrico halla sido capaz de producir. La fuerza y poder que existe dentro del cuerpo humano, llamada también vitalidad humana o magnetismo es mucho mas grande y dinámica de lo que nos imaginamos. Tenemos también el poder, la fuerza potente que se manifiesta a través de la mente humana.

\section{FUERZAS EN EL HOMBRE}

El hombre tiene a su alrededor y en sí mismo, muchas fuerzas que puede usar, debe aprender a emplearlas y tal conocimiento le da el control y uso de los poderes. No hay fuerza tan grande que la que viene por el conocimiento. Reflexione sobre los tiempos de la Edad Media y verá lo que la falta de conocimiento ha significado para el hombre.

Ha pasado ya la negra y tenebrosa Edad Media, y hoy día algunos saben como usar las oportunidades y fuerzas que los rodean y otros no, los que saben tienen éxito en los negocios, son felices y hacen bien a los demás; pero otros son fracasados, trabajan solos en las tinieblas, quejándose constantemente, listos para dañar a los demás, y sin encontrar nunca la felicidad. Sin embargo la idea es asociarnos para adquirir el conocimiento que nos hará poderosos en el bien. Las fuerzas de la naturaleza no pueden usarse fácilmente para cosas negativas, mientras que para el bien pueden usarse por cualquiera que posea la llave.

Hasta aquí hemos visto que el hombre tiene dentro de sí una gran fuerza o poder, y que también tiene una mente que le permite armonizar su cuerpo y sus facultades con las grandes fuerzas del universo. Ahora deseo ayudar a comprender como usar algunas de esas fuerzas. 
Una de las mas grandes fuerzas en el cuerpo humano es la Energía Nerviosa, su fuente está en la fuerza vital de la vida. La ciencia ha denominado a esta energía "Energía Eléctrica Nerviosa" porque se ha descubierto que es la naturaleza vibratoria, como la electricidad. La energía nerviosa es una fuerza maravillosa que recorre todo el cuerpo, igual que los alambres eléctricos que se usan en un edifico para transmitir la corriente o fuerza de un lugar a otro.

Ahora bien, hay ciertos lugares en el cuerpo en los que esta energía nerviosa, eléctrica o vibratoria, se manifiestan con mas potencia. En cada músculo, por supuesto, la energía nerviosa actúa vigorosamente, como también lo hace en los principales vasos sanguíneos, la energía fluye con fuerza y pasa o se escapa por lo que pudiéramos llamar las "terminales" de los nervios principales o nervios troncales, encontramos que esto es así en dos terminales nerviosas muy importantes del cuerpo -nuestras manos-. En efecto, las puntas de los dedos son extremidades de nervios muy importantes y constituyen terminales nerviosas que los místicos del pasado usaban en sus trabajos. Los llamados curanderos por magnetismo, usan sus manos para curar, porque han descubierto que hay cierto poder en ellas. Pero el poder más grande está en los primeros dedos, es decir, en el pulgar el índice y el dedo medio de ambas manos, hasta las puntas de estos llega cierto nervio (llamado en fisiología el nervio radial), el cual en efecto irradia cierto poder que puede ser usados para muchos propósitos. Con instrumentos delicados es posible medir esta energía nerviosa y bajo ciertas condiciones, percibirla subjetivamente.

\section{LA EDUCACIÓN FÍSICA: ¿UN CAMINO CON CORAZON?}

Cualquier camino es tan sólo un camino y no es ninguna ofensa, ni para uno mismo ni para los demás, abandonarlo si así te lo dicta tu corazon...

Mira y observa todos los caminos de cerca y deliberadamente. Hazlo tantas veces corno creas necesario. Después, pregúntate a ti mismo, y sólo a ti mismo lo siguiente... ¿Tiene este camino corazón? Si lo tiene, el camino es bueno, si no lo tiene no sirve para nada.

Carlos Castañeda, Las Enseñanzas de Don Juan

\section{EL CUERPO QUE SE DA CUENTA}

\section{La Percepción Corporal}

La primera verdad de la maestría del estar consciente de ser según nos lo revela Castañeda en el "Fuego Interno" se refiere a que los seres humanos somos parte y estamos suspendidos en las emociones del Águila (VII-58). Esta verdad en particular como las otras cinco de la misma Maestría, aluden al hecho de que somos seres luminosos; un tipo específico en medio de un universo, campos de energía al que don Juan Ilama "Las Emanaciones del Águila".

La porción de energía que somos está contenida durante nuestra vida en una forma o molde, conocido como la forma humana (VII-28). Y la característica esencial de este campo de energía es percibir; por eso decía don Juan a Carlos que somos un sentimiento, un darse cuenta encajonados aquí al tiempo que le golpeaba levemente el pecho (IV-20).

Hay que notar que cuando hablamos de nuestra naturaleza de perceptores, no nos referimos al ego -que no es perceptor- si no verbalizador sino a nuestro cuerpo como 
campo de energía. Por lo tanto aquí no tiene sentido tratar de determinar sobre que parte del cuerpo perciben.

La percepción corporal tiene lugar con la totalidad del cuerpo, aun con aquella parte que trasciende nuestra piel y que a los ojos de los videntes, nos da el aspecto de "Enormes huevos luminosos"

(II-29).

Esta percepción corporal se nos presenta como opuesta a la percepción ordinaria que es aparente y que logramos a través de una combinación de los dictados del ego, la historia personal y el trabajo de los sentidos. La percepción corporal en cambio, es directa y no admite interpretaciones. La división mente-cuerpo carece de sentido en ese contexto, desde que el cuerpo es asimilado como campo de energía del capullo luminoso y los campos de energía externos.

Es por ello que desde el principio de su relación, don Juan insiste a Carlos en poner más atención a lo que siente y se olvide pensar. Le habla de que el cuerpo aprende y de que el cuerpo sabe. El sustento de todo lo que se enseña tiene una dimensión corporal en tanto que radica en actos y no en pensamientos o palabras, por eso lo que hace el guerrero, son sus actos, antes que su filosofía.

El conocimiento del cuerpo es una posibilidad esencialmente distinta del conocimiento tal como lo entiende la moderna cultura occidental; en la cual se asocia a la capacidad de elaborar enunciados verbales o mentales, que supuestamente revelen las características de las cosas o proceso conocido.

Por lo que toca a la percepción, la gente civilizada suele suponer que es algo que se realiza sólo por medio de los cinco sentidos y el primerísimo lugar a través de la vista, para luego procesar todo aquello que reporten los sentidos en el centro del pensamiento que ubicamos detrás de los ojos. Sin embargo la propuesta de don Juan es que podemos utilizar los sentidos de modos diferentes a los ordinarios, que podemos saber la naturaleza de las cosas y la realidad sin tener que pensarlo, que el cuerpo tiene su propio modo de conocimiento silencioso y su propia memoria.

La percepción corporal a la que se refiere la obra de Castañeda alude a un conocimiento silencioso que no incluye palabras ni pensamientos. Es el cuerpo y el mundo en interacción.

\section{EL CUERPO MECANICO CUANTICO}

Para un escéptico, esta proposición sonará puramente subjetiva, pero dentro de nuestras células se producen constantemente acontecimientos cuánticas que desafían al tiempo lineal. La inteligencia del ADN opera simultáneamente en el pasado, en el presente y en el futuro. Del pasado toma el plano de la vida, aplicando al presente solo la más ínfima parte de la información necesaria para el funcionamiento celular (quizás una mil millonésima parte de su base total de datos) y reserva para el futuro la información que aplicará dentro de muchos años. La doble hélice es el deposito cuántico de su futuro; allí está el tiempo, comprimido y encerrado hasta que haga falta. En el momento en que fuiste concebido, tus genes obtuvieron el control de toda una vida de acontecimientos que se desplegarían en secuencia exacta. Por ejemplo: tus manos emergieron del vientre, como amorfos grumos de células, al comienzo, después como bultos nudoso que convirtieron en aletas parecidas a las del pez, pies anfibios, zarpas animales y, finalmente, en manos humanas. 
Esos grumos, bultos, aletas, pies y zarpas aún están presentes como datos archivados en tus genes, al igual que las manos de tu infancia, la edad adulta y la ancianidad. En el plano cuántico, vives todas esas edades al mismo tiempo, como los seres humanos somos tanto físicos como cuánticos, vivimos existencias multidireccionales. En este momento estas en dos lugares al mismo tiempo, uno es el mundo visible y sensorial, donde tu cuerpo se ve sujeto a todas las fuerzas de la naturaleza de allí fuera. El viento te irrita la piel; el sol la quema; en invierno morirías congelado si no tuvieras techo, el ataque de gérmenes y virus hace que tus células enfermen. Pero también ocupas el mundo cuántico, donde todo eso cambia, si te sumerges en la bañera, tu conciencia no se moja. Las limitaciones de la vida física tienen mucha menos importancia en el mundo cuántico; con frecuencia, ninguna. El frío del invierno no te entumece los recuerdos, el calor de una noche de calicula no hacen que suden tus sueños.

Reúne todos los acontecimientos cuánticos que hay en tus células; la suma total es tu cuerpo mecánico cuántico, que opera según su propia filosofía invisible. Tu cuerpo mecánico cuántico es conciencia en movimiento y parte del externo campo de conciencia que existe en ola fuente de la creación. La inteligencia que hay dentro de nosotros irradia como luz, cruzando la frontera entre el mundo cuántico y el mundo físico, unificando ambos en un constante diálogo subatómico. Tu cuerpo físico y tu cuerpo mecánico cuántico merecen por igual el nombre de hogar: son como universos paralelos entre los cuales viajas sin siquiera pensarlo.

Hay cierta marea o movimiento cósmico con el cual se explica tanto la formación de los universos como el influjo de la vida y la conciencia del hombre. Dentro de nosotros se encuentran no simples poderes aislados, sino fuerzas universales en acción. ¡Cómo es arriba, así es abajo!

La más hermosa experiencia que podemos gozar es la percepción de lo misterioso. Es ésta la emoción fundamental que da origen y vida a la verdadera ciencia. Quien no la conozca, o no pueda sentir admiración o maravilloso asombro ante lo misterioso, podría considerarse muerto.

Albert Einstein

\section{LA LIBERTAD Y EL CONOCIMIENTO COMO RESPONSABILIDAD PERSONAL}

Una de mis propuestas fundamentales de trabajo, es que podemos darnos a la tarea de rescatar nuestras posibilidades desconocidas de conciencia, sin que sea indispensable para lograrlo la presencia específica de alguien más. Parto de la base de que en nuestro propio ser se encuentran las herramientas que necesitamos y que si estamos realmente dispuestos a dejar de ser "intelectuales de sofá" para convertirnos en practicantes comprometidos, nos basta con la oportunidad mínima que tarde o temprano llega y que en el caso específico de cada uno puede ser un místico, un brujo, un libro, un grupo de trabajo o cualquier otro que funcione como apoyo. Lo que cuenta finamente, es el trabajo que cada uno esté dispuesto a ser. $Y$ lo que pienso respecto al rescate de nuestras posibilidades desconocidas se aplica también a la búsqueda de la libertad, que en ningún caso puede venirnos desde afuera, va que es en realidad una responsabilidad personal. Hablo de una libertad que podamos concebir o intuir aún sin entenderla en el contexto de nuestra propia vida, ya que una visión libresca o fantasiosa de la libertad, tiene la desventaja de ser tan perfecta y ajena, que no encontramos como acometerla, 
quedándonos entonces pasivos frente a las limitaciones de nuestra existencia diaria. Propongo una aproximación más vivencial y menos mental a la libertad y el conocimiento. Y es que para mí, el consenso final del conocimiento de cualquier ser humano se expresa en su forma de vida y no en sus palabras.

\section{BIBLIOGRAFÍA}

CASTAÑEDA, Carlos: El fuego interno, Editorial Swam, 1980.

Relatos de poder, Primera Ed. En Español 1976, Fondo de Cultura Económica México. Una realidad aparte, México Fondo de Cultura Económica 1974. 